Strahlenther Onkol 2014 · 190:792-797

DOI 10.1007/s00066-014-0651-z

Received: 30 January 2014

Accepted: 27 February 2014

Published online: 1 April 2014

(c) The Author(s) 2014. This article is published

with open access at Springerlink.com

Ingmar Schlampp ${ }^{1}$. Stefan Rieken ${ }^{1}$. Daniel Habermehl ${ }^{1}$. Thomas Bruckner ${ }^{2}$. Robert Förster ${ }^{1}$. Jürgen Debus ${ }^{1} \cdot$ Harald Rief $^{1}$

'Department of Radiation Oncology, University Hospital of Heidelberg, Heidelberg, Germany

${ }^{2}$ Department of Medical Biometry, University Hospital of Heidelberg, Heidelberg, Germany

\title{
Stability of spinal bone metastases in breast cancer after radiotherapy
}

\section{A retrospective analysis of 157 cases}

The skeleton is the most frequently affected organ in metastatic breast cancer [1]. Up to $2.6 \%$ of all breast cancer patients have bone metastases at the initial diagnosis and up to $15 \%$ will develop bone metastases within 15 years $[2,3]$.

Drug-resistant pain, pathological fractures, and neurological complications are the most common consequences, inducing significant morbidity and impairment of quality of life. The treatment of bone metastases requires a multidisciplinary approach with surgical, pain therapeutical, oncological, and radiotherapeutical care.

Indications for radiotherapy (RT) are pain, existing or impending instability, neurological symptoms due to compression of the spinal cord, or previous surgical intervention [4]. RT offers pain relief in $50-80 \%$ of patients. The benefit of RT concerning pain and recalcification of osteolytic metastases may be greater when the therapy is combined with concomitant administration of bisphosphonates [1].

Orthopedic thoracic corsets are used to prevent vertebral fractures and consecutive spinal cord compression. Immobilization for pain and suspected instability are consequences of spinal metastases. The use of a validated scoring system to assess the stability of spinal bone metastases may prevent physicians from overdiagnosis of instability and, thus, improve the quality of life in palliative-stage patients.

The aim of this retrospective analysis of breast cancer patients with bone metas- tases was to systematically assess the bone lesions in terms of stability, fractures prior to and following RT, survival, and predictive factors for stability.

\section{Patients and methods}

This analysis was based on 115 patients, whose 157 osseous lesions were treated by RT for metastases of the vertebral column due to histologically diagnosed breast carcinoma from January 2000 to January 2012. Patients underwent regular followup examinations including computer tomography (CT) imaging.

Patients with osteolytic metastases, localization in the thoracic and lumbar spine, and a minimum duration of follow-up treatment of 6 months were included in this retrospective analysis. Patient data were taken from a cancer registry. Patients who were irradiated in several regions were regarded separately for each region in our analysis. Within each region, the most severe metastasis according to the Taneichi score was included in the analysis [6]. Accordingly, 115 patients with 157 irradiated regions, including 480 vertebral bodies in the thoracic and lumbar spine, were evaluated. For each region one metastasis with the highest probability of collapse according to the Taneichi score was chosen for the examination.

All patients were female. The most frequent histological type was invasive ductal carcinoma (79\%). The Karnofsky Performance Status Scale (KPS) was used to assess performance status [5]. The diagnosis of bone metastasis was made on the basis of the CT or magnetic resonance imaging (MRI) findings or bone scintigraphy investigations. The patient characteristics are summarized in $\bullet$ Table 1.

The stability of each affected vertebral body was assessed according to the $\mathrm{Ta}$ neichi score on the basis of the CT image

\section{Table 1 Patient characteristics}

\begin{tabular}{|c|c|c|}
\hline & $n$ & $\%$ \\
\hline \multicolumn{3}{|l|}{ Age at radiotherapy (years) } \\
\hline Median (range) & \multicolumn{2}{|c|}{$60(32-88)$ years } \\
\hline \multicolumn{3}{|l|}{ Karnofsky scale } \\
\hline $30-60$ & 26 & 17 \\
\hline $70-80$ & 102 & 65 \\
\hline $90-100$ & 29 & 18 \\
\hline \multicolumn{3}{|l|}{ Histology } \\
\hline Inflammatory & 1 & 1 \\
\hline Invasive ductal & 124 & 79 \\
\hline Invasive lobular & 31 & 20 \\
\hline Invasive papillary & 1 & 1 \\
\hline \multicolumn{3}{|l|}{ Site } \\
\hline Thoracic & 116 & 74 \\
\hline Lumbar & 41 & 26 \\
\hline \multicolumn{3}{|l|}{ Distant metastases } \\
\hline Brain & 14 & 9 \\
\hline Lung & 26 & 17 \\
\hline Liver & 28 & 18 \\
\hline Others & 22 & 15 \\
\hline \multicolumn{3}{|c|}{ Immunohistochemistry positivity } \\
\hline Estrogen receptor & 131 & 83 \\
\hline $\begin{array}{l}\text { Progesterone } \\
\text { receptor }\end{array}$ & 124 & 79 \\
\hline Her2-neu & 43 & 27 \\
\hline
\end{tabular}




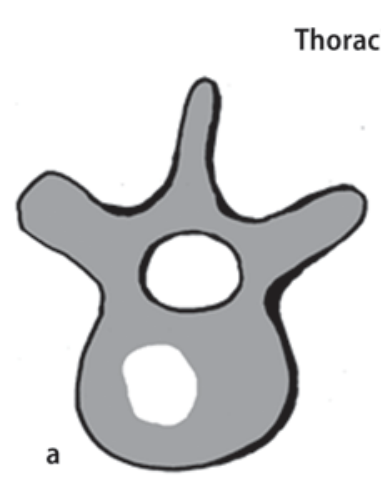

Thoracic spine
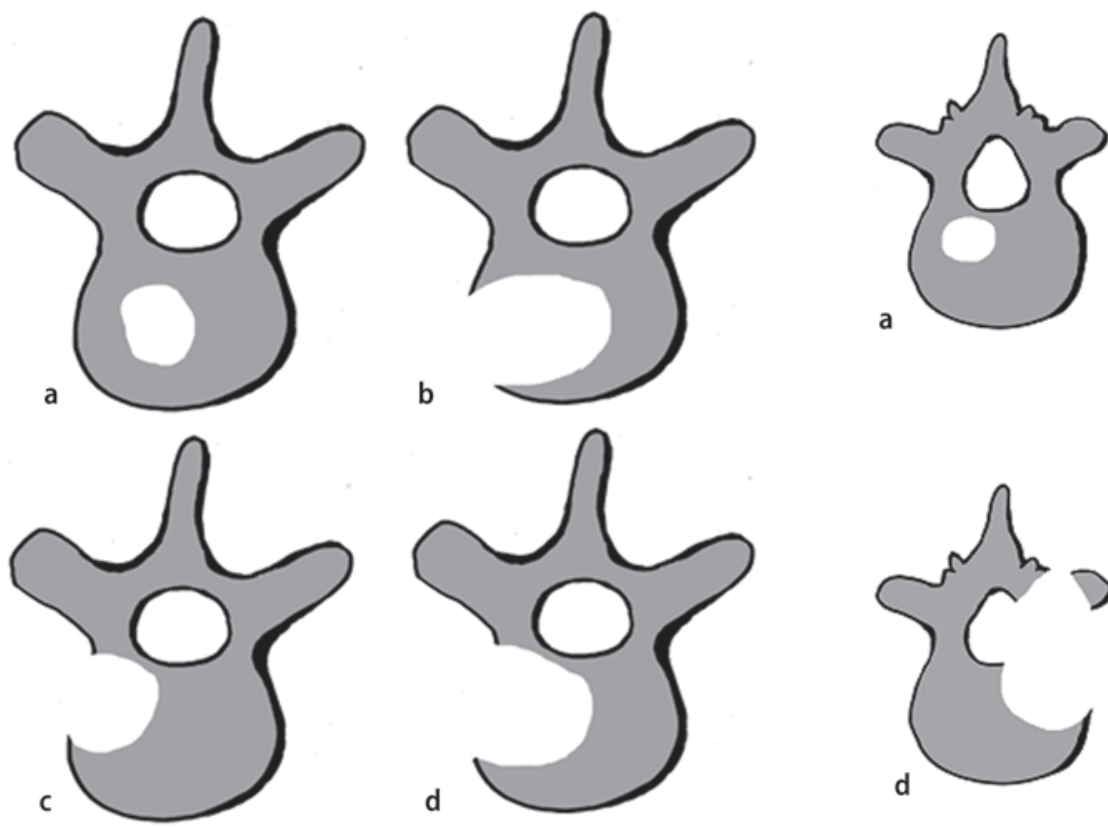

Lumbar spine
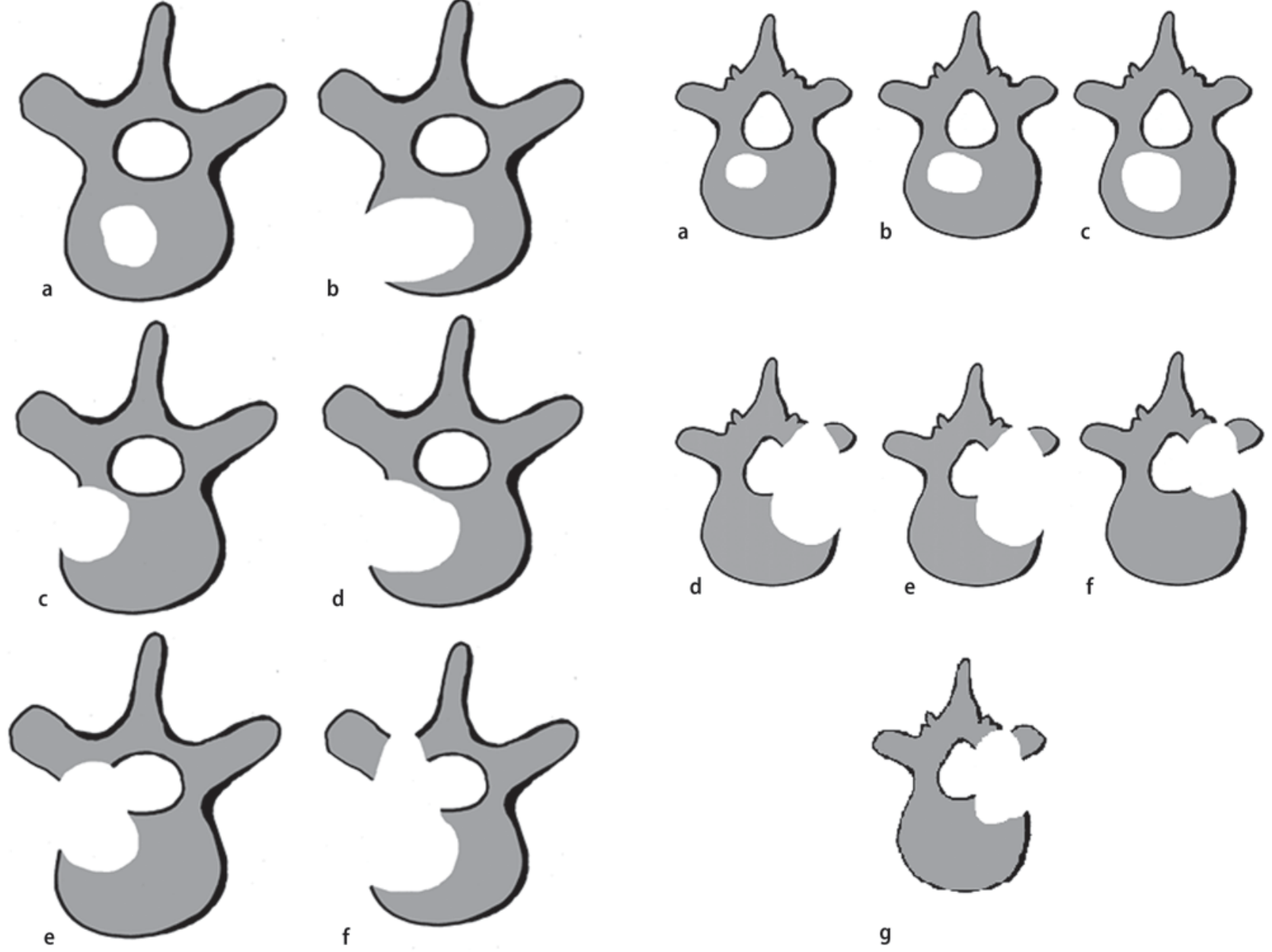

g

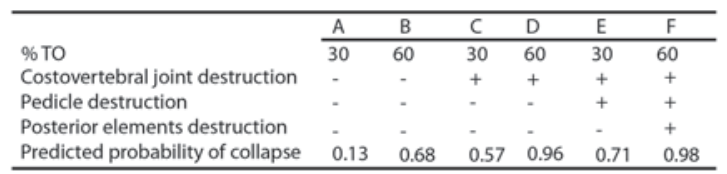

\begin{tabular}{llllllll}
\hline & $\mathrm{A}$ & $\mathrm{B}$ & $\mathrm{C}$ & $\mathrm{D}$ & $\mathrm{E}$ & $\mathrm{F}$ & $\mathrm{G}$ \\
\cline { 2 - 7 } \% TO & 20 & 30 & 40 & 40 & 60 & 5 & 20 \\
Pedicle destruction & - & - & - & + & + & + & + \\
Posterior elements destruction & - & - & - & - & & + & + \\
Predicted probability of collapse & 0.07 & 0.25 & 0.6 & 0.99 & 0.99 & 0.06 & 0.38 \\
\hline
\end{tabular}

Fig. $1 \Delta$ Applied score for osteolytic metastases of the thoracic and lumbar spine [6]

recorded before RT to plan treatment and also in the follow-up stage 3 and 6 months after radiotherapy [6].

The osteolytic metastases were rated on a scale from A to G. Subtypes A to C were defined as stable, subtypes $D$ to $G$ as unstable (• Fig. 1).

Most patients received additional chemotherapy, endocrine therapy, or bisphosphonates before and after RT. After RT, $91 \%$ of the lesions were treated with bisphosphonates (• Table 2), and $61 \%$ of the patients were equipped with an orthopedic thoracic corset.
This study was approved by the institutional ethics committee on 22 October 2012 (nr. S-513/2012).

\section{Radiotherapy}

RT was applied for instability in 67 and $52 \%$ of patients due to pain, when regarding the documented indication for therapy. The treatment was carried out at the department of radiation oncology. RT was planned using virtual simulation based on CT scans, and was performed over a dorsal photon field with energy of $6 \mathrm{MV}$. The planning target volume (PTV) covered the vertebral body affected as well as bodies immediately above and below. The most frequent radiation schedule was 10 fractions of $3 \mathrm{~Gy}$ in $57 \%$ of cases (- Table 2). The fractionation schedule was selected individually for each patient, depending on the patient's general state of health, the current staging, response to current therapy, and the respective prognosis.

\section{Statistical analysis}

The empirical distribution of continuous variables is described by the number of observations, mean and standard deviation; the description of categorical vari- 
ables includes the number and percentage of patients belonging to the relevant categories.

The univariate chi-square test was used to evaluate the prognostic factors for the endpoint stabilization of spinal metastases for the factors age, KPS, histology, number of metastasis ( 1 vs. $>1$ ), irradiated area (thoracic vs. lumbar spine), hormone receptor status (positive vs. negative), overall dose, and concomitant therapy (chemotherapy, hormone drug therapy, bisphosphonates) separately for the period within 6 months before and after RT.

Survival times are presented graphically, using the Kaplan-Meier method. Patients who were lost to follow-up were included in the statistics as censored observations.

"Bone survival" was defined as the time from the first diagnosed spinal metastases to death. Overall survival was defined as the time from the initial diagnosis of breast cancer to death.

For the distribution of Taneichi score subtypes before and 6 months after RT, the Bowker test was used. Kappa statistics were calculated to detect possible asymmetry in the distribution of the Taneichi score over time.

Overall survival and bone survival were calculated for subgroups divided by the number of irradiated metastases, to account for the acceptance that patients with one metastasis requiring treatment will have a better prognosis than those with multiple metastases.

\section{Results}

The median follow-up of all patients was 16.7 months (mean 19.9, range 0.4-74.7 months). Thirty patients (19\%) died during follow-up. Seventy patients (61\%) had only bone metastases, 45 patients (39\%) had metastases in other distant organs such as t5he liver $(n=22)$, lung $(n=19)$, and brain $(n=11)$.

Before RT, $46 \%(n=72)$ of the lesions were classified as stable according to the Taneichi score. Of the stable bone metastases, none were rated unstable in the further course of study $(p<0.001, \mathrm{McNemar}$ test).

Of the 85 patients (54\%) in whom the metastases were classified as unstable pri-

Strahlenther Onkol 2014 · 190:792-797 DOI 10.1007/s00066-014-0651-z

๑) Springer-Verlag Berlin Heidelberg 2014

\section{Schlampp · S. Rieken · D. Habermehl · T. Bruckner · R. Förster · J. Debus · H. Rief Stability of spinal bone metastases in breast cancer after radiotherapy. A retrospective analysis of 157 cases}

\section{Abstract}

Purpose. This retrospective analysis was performed to evaluate osteolytic bone lesions of breast cancer in the thoracic and lumbar spine after radiotherapy (RT) in terms of stability using a validated scoring system.

Methods. The stability of 157 osteolytic metastases, treated from January 2000 to January 2012, in 115 patients with breast cancer was evaluated retrospectively using the Taneichi score. Predictive factors for stability were analyzed and survival rates were calculated.

Results. Eighty-five (54\%) lesions were classified as unstable prior to RT. After 3 and 6 months, 109 (70\%) and 124 (79\%) lesions, respectively, were classified as stable. Thirty fractures were detected prior to RT, and after
RT seven cases (4.5\%) with pathologic fractures were found within 6 months. None of the examined predictive factors showed significant correlation with stability 6 months after RT. After a median follow-up of 16.7 months, Kaplan-Meier estimates revealed an overall survival of $83 \%$ after 5 years.

Conclusion. The majority of patients showed an improved or unchanged stability of the involved vertebral bodies after 6 months. The patients showed only minor cancer-related morbidity during follow-up and reached comparably high survival rates.

Keywords

Bone metastases · Spine · Breast cancer . Stability · Fracture

\section{Stabilität von Wirbelsäulenmetastasen bei Brustkrebs nach Radiotherapie. Eine retrospektive Analyse von 157 Fällen}

\section{Zusammenfassung}

Hintergrund. Die retrospektive Analyse untersuchte osteolytische Knochenmetastasen von Patienten mit Mammakarzinom der thorakalen und lumbalen Wirbelsäule nach Radiotherapie (RT) hinsichtlich Stabilität anhand eines validierten Scores.

Methoden. Die Stabilität von 157 osteolytischen Metastasen bei 115 Patienten mit Brustkrebs, behandelt von Januar 2000 bis Januar 2012, wurde retrospektiv anhand des Taneichi-Scores evaluiert. Prognostische Faktoren bezüglich Stabilität und Überlebensraten wurden analysiert.

Ergebnisse. Vor RT wurden 85 Läsionen (54\%) als instabil gewertet. Nach 3 und 6 Monaten wurden 109 (70\%) und 124 (79\%) Läsionen als stabil klassifiziert. Vor RT wurden 30 Frakturen gefunden, nach RT zeigten sich
7 weitere $(4,5 \%)$ pathologische Frakturen. Kein prognostischer Faktor hatte signifikanten Einfluss auf die Stabilität 6 Monate nach RT. Nach einer Beobachtungszeit von median 16,5 Monaten ergab sich aus der KaplanMeier-Berechnung eine Gesamtüberlebenszeit von $83 \%$ nach 5 Jahren.

Schlussfolgerung. Die Mehrheit der Patienten zeigte eine verbesserte oder konstante Stabilität der befallenen Wirbelkörper nach 6 Monaten. Die analysierten Patienten zeigten nur geringe tumorassoziierte Einschränkungen während der Nachbeobachtungszeit und erreichten hohe Überlebenszeiten.

\section{Schlüsselwörter}

Knochenmetastasen - Wirbelsäule

Brustkrebs · Stabilität · Fraktur or to RT, 24 patients were classified as stable after 3 months, and 35 patients stable after 6 months. This means that in total, 61 and $68 \%$ of the bone metastases were stable after 3 and 6 months, respectively (- Table 3).

The evaluation of the distribution of subtypes A to $G$ showed a major change in the direction of improvement over the course of time. Improvement in the score occurred in $61 \%$ patients $(n=95)$.
Improvement of stability was detected in $22 \%(n=35)$ of all cases. This corresponds to an improvement of stability in $45 \%$ of all unstable lesions $(n=85)$. Deterioration of stability was detected in $2 \%$ of cases $(n=3)$. The Bowker test shows the distribution pattern of the subtypes according to the Taneichi score prior to and 6 months after RT. Asymmetry was apparent $(p=0.0001)$ and the corre- 


\begin{tabular}{|c|c|c|}
\hline Radiotherapy (RT) & $n$ & $\%$ \\
\hline $10 \times 3 \mathrm{~Gy}$ & 89 & 57 \\
\hline $14 \times 2.5 \mathrm{~Gy}$ & 25 & 16 \\
\hline $20 \times 2 \mathrm{~Gy}$ & 38 & 25 \\
\hline Others & 3 & 2 \\
\hline \multicolumn{3}{|l|}{ Irradiated vertebrae } \\
\hline 3 & 70 & 45 \\
\hline $4-6$ & 45 & 29 \\
\hline$>6$ & 42 & 27 \\
\hline \multicolumn{3}{|l|}{ Concomitant therapy } \\
\hline \multicolumn{3}{|l|}{ Prior to RT } \\
\hline Chemotherapy & 55 & 35 \\
\hline Endocrine therapy & 58 & 37 \\
\hline Bisphosphonates & 59 & 38 \\
\hline \multicolumn{3}{|l|}{ After RT } \\
\hline Chemotherapy & 81 & 52 \\
\hline Endocrine therapy & 109 & 69 \\
\hline Bisphosphonates & 143 & 91 \\
\hline \multicolumn{3}{|l|}{ Stability } \\
\hline Stable prior to RT & 72 & 46 \\
\hline $\begin{array}{l}\text { Stable } 3 \text { months } \\
\text { after RT }\end{array}$ & 97 & 62 \\
\hline $\begin{array}{l}\text { Stable } 6 \text { months } \\
\text { after RT }\end{array}$ & 107 & 68 \\
\hline
\end{tabular}

Table 4 Distribution of subtypes A to $G$ over the course of time (0-6 months)

Bowker test

\begin{tabular}{|lllllllll}
\hline \multicolumn{10}{|c}{ 6 months after RT } \\
\hline $\begin{array}{l}\text { Prior } \\
\text { to RT }\end{array}$ & & A & B & C & D & E & F & G \\
\hline & A & 25 & 1 & 0 & 1 & 0 & 0 & 0 \\
\hline & B & 11 & 17 & 0 & 0 & 0 & 0 & 0 \\
\hline C & 4 & 2 & 9 & 0 & 2 & 0 & 0 \\
\hline D & 5 & 2 & 4 & 12 & 0 & 0 & 0 \\
\hline E & 8 & 2 & 0 & 2 & 20 & 0 & 0 \\
\hline F & 10 & 2 & 3 & 0 & 2 & 10 & 0 \\
\hline G & 2 & 0 & 0 & 0 & 0 & 1 & 0 \\
\hline
\end{tabular}

lation (weighted kappa $=0.67$ ) was good (• Table 4).

Before RT, 30 patients had pathological fractures within the irradiated region. During the follow-up, in seven cases $(4.5 \%)$ new fractures were found, of which all but one had been evaluated as unstable before RT ( $n=6)$.

Using fractionation patterns with overall doses of 30-40 Gy, there was no correlation between overall dose and stability after RT $(p=0.12)$.

Furthermore, there was no significant correlation in the univariate analy-

Table 3 Results of prognostic factors related to stability

$$
\text { n } \quad \%
$$

\begin{tabular}{|c|c|c|c|}
\hline Stability & & & \\
\hline & Prior to RT & 72 & 54 \\
\hline & 3 months after RT & 96 & 61 \\
\hline & 6 months after RT & 107 & 68 \\
\hline General & & & \\
\hline & & $p$ value & \\
\hline & Age & 0.27 & \\
\hline & KPS & 0.47 & \\
\hline & Histology & 0.90 & \\
\hline & Number of metastases ( 1 vs. $>1$ ) & 0.27 & \\
\hline & Area (thoracic vs. lumbar spine) & 0.97 & \\
\hline & $\begin{array}{l}\text { Hormone receptor (positive vs. } \\
\text { negative) }\end{array}$ & 0.18 & \\
\hline Therapy & & & \\
\hline & Overall dose & 0.12 & \\
\hline Therapy & before RT & & \\
\hline & Chemotherapy (yes vs. no) & 0.90 & \\
\hline & Hormone therapy (yes vs. no) & 0.12 & \\
\hline & Bisphosphonates (yes vs. no) & 0.62 & \\
\hline Therapy & & & \\
\hline & Chemotherapy (yes vs. no) & 0.21 & \\
\hline & Hormone therapy (yes vs. no) & 0.88 & \\
\hline & Bisphosphonates (yes vs. no) & 0.36 & \\
\hline
\end{tabular}

sis between stability after RT and the potential predictive factors such as bisphosphonates, chemotherapy, and hormone therapy before and after RT. Further factors tested in the univariate analysis were age, KPS, hormone receptor status, histology, and location of the examined metastasis (lumbar spine vs. thoracic spine;

\section{- Table 3).}

Overall survival was $83 \%$ at 5 years for all patients (• Fig. 2). The 5-year survival rate for patients with one treated metastasis and more than one metastasis was 88 and $79 \%$, respectively. Bone survival for all patients was $69 \%$ (• Fig. 3), and 74 and $59 \%$ for patients with one and more than one treated metastasis, respectively.

The difference between the subgroups of patients with one and more than one metastasis in both measured periods, overall survival and bone survival, was not significant, with a $\mathrm{p}$ value of 0.12 and 0.078 , respectively, in the log-rank test.

\section{Discussion}

Besides pain, the reduced stability is the most frequent reason for radiation of bone metastases. The scoring system by
Taneichi et al. classifies osteolytic metastases of the thoracic and lumbar spine by risk factors such as tumor size and involvement of costovertebral joints for the thoracic region (Th 1 to 10) and by tumor size and destruction of the pedicles for the lumbar region (Th11, Th12, and all lumbar vertebrae). Posterior elements seem to have a major impact on stabilization, which was found in biometrical models of the thoracic and lumbar spine vertebrae [7-9].

Before RT, $46 \%$ of the lesions $(n=72)$ were classified as stable, and after 6 months $70 \%(n=110)$ were stable. Patients benefit from stabilized metastases in daily life, as soon as they can omit their corset.

In patients who were treated before the validated score was introduced in the facility in 2011, stability of osteolytic bone lesions was estimated on the basis of several factors such as involvement of the rear edge at the vertebral foramen and pain. According to the documentation, $67 \%$ of the irradiated metastases were unstable. Applying the validated score retrospectively, $54 \%$ of the metastases were 


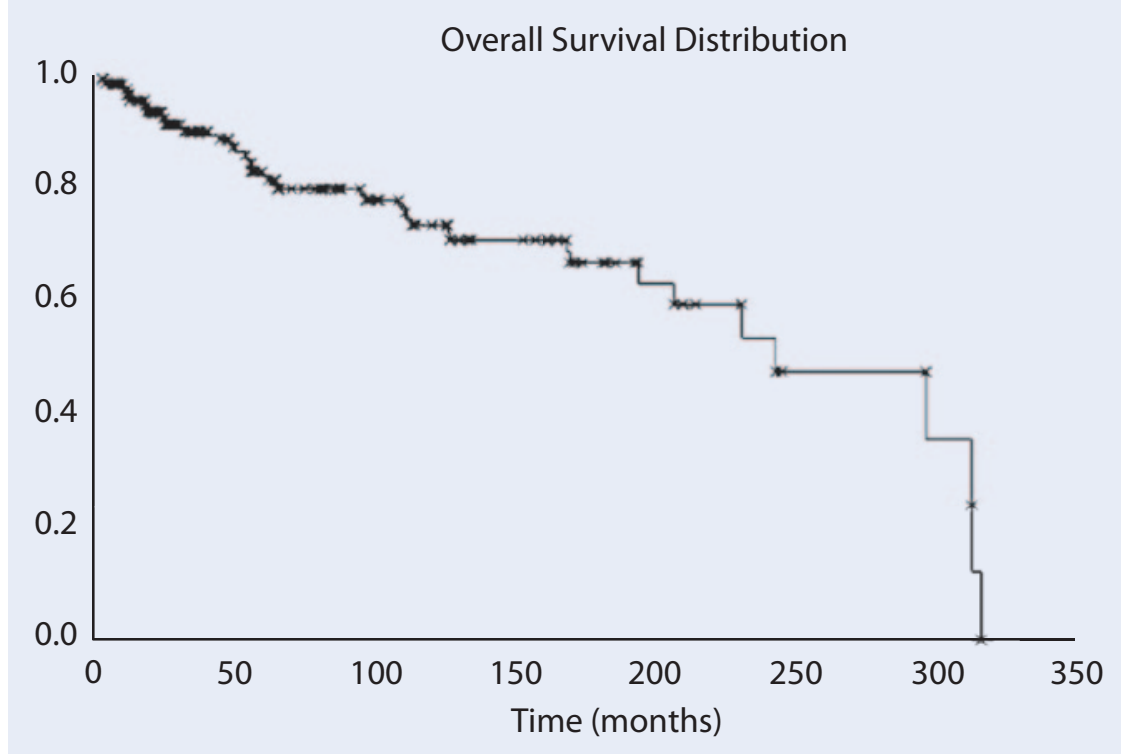

Fig. $2 \Delta$ Overall survival

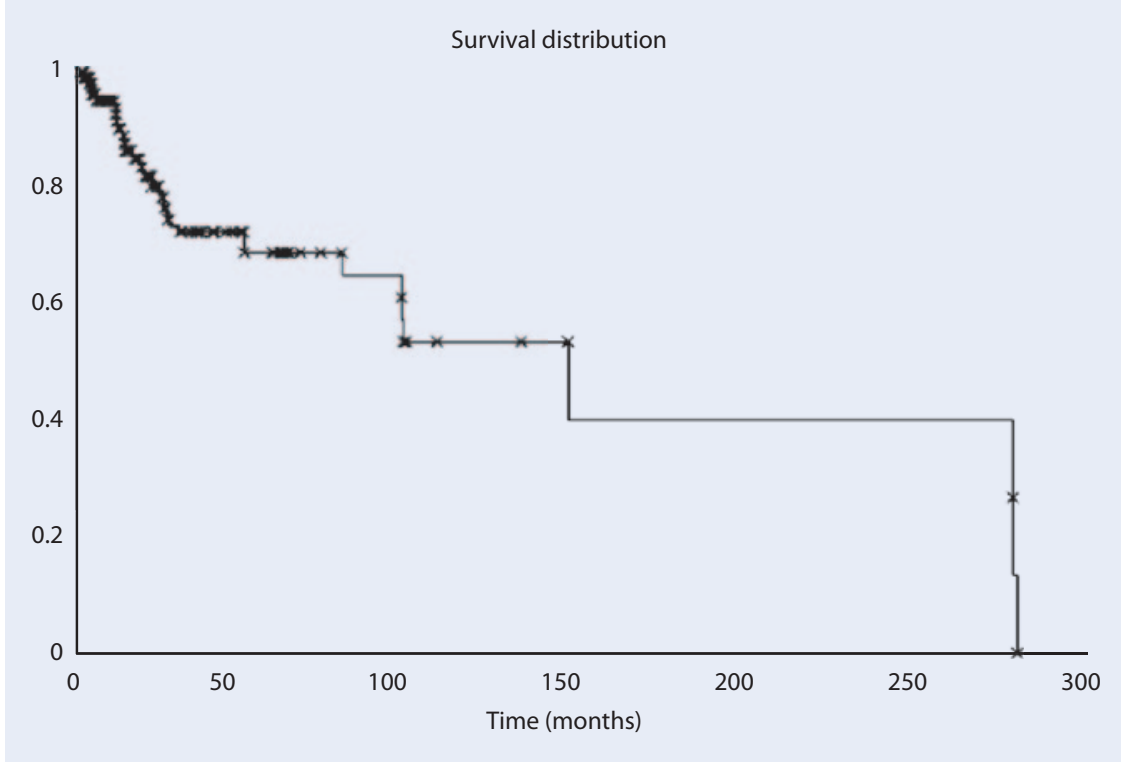

Fig. $3 \Delta$ Bone survival

rated unstable. The difference is result of the changed criteria.

Fractures were detected in 30 lesions. The follow-up examinations revealed seven patients with progressive bone destruction or new fracture.

According to the literature, symptomatic spinal cord compression in patients with bone metastases can be expected in $10 \%$ of all cases [4]. The patients included in our analyses showed less frequent and less severe neurologic deficits. The reasons might be a preference of sur-
Complete paraplegia developed in one patient several years after RT.

The rarity of neurological signs might be caused by the preference of surgery in these patients, as it offers immediate decompression of the spinal cord and stabilization [10]. In the analyzed cases, RT was preferably applied to prevent neurologic symptoms and pain caused by collapsing metastases.

All examined factors such as age, KPS, hormone receptor status, histology of the primary tumor, and location of the examined metastasis failed to show significant influence on the probability for restabilization after RT. The concomitant therapy with hormone therapy, chemotherapy, and bisphosphonates therapy also did not show any favorable influence in our analysis. Similar results were already observed in an analysis of bone metastases in lung cancer patients [11].

The predominately used dose schedules for the analyzed cases were 10 fractions of $3 \mathrm{~Gy}, 14$ fractions of $2.5 \mathrm{~Gy}$, and 20 fractions of $2 \mathrm{~Gy}$. As suggested by current guidelines, the fractionation schemes were individually selected regarding multiple factors such as prognosis and general state [11]. One can assume that prolonged radiation has a longer lasting effect on bone metastases and a minor probability of in-field recurrences. Considering the available data from the literature, there seem to be few distinctions between the applied fractionations $[1,4]$. The analysis consistently showed no significant difference in the fractionation schedules used in our study.

Remarkably, this analysis focused on stabilization of irradiated metastasis within 6 months. This implies that there might be limitations, when examining the influence of systemic or long-term therapies.

Improvements in the therapy of bone metastases were accomplished by concomitant drug therapy such as bisphosphonates [12]. Several trials showed that concomitant bisphosphonates therapy seems to be secure and is assumed to support recalcification. Nevertheless, there is no evidence from controlled prospective trials of the superiority of a combined therapy compared with RT alone [1]. One recent similar analysis, examining predictive factors for survival of de novo bone- 
metastasized breast cancer patients, suggests that bisphosphonate treatment might be linked to longer overall survival. According to this report, patients receiving hormone therapy or chemotherapy had no significant survival benefit [13]. Further reports did not find a benefit when comparing the hormone receptor status with the probability for skeletal complications [14]. In our analysis we could not detect a benefit for hormone or chemotherapy after RT concerning the endpoint stabilization.

The median overall survival for metastatic breast cancer is long (several years) when compared with other tumors such as lung cancer [15-17]. In our analysis, we measured a survival of $82 \%$ after 5 years, which is longer than the overall survival measured in similar studies [10]. The extended survival might be a manifestation of the selection criteria, by only including patients with at least 6 months of followup. This is also illustrated by the high initial KPS with median value of 80 .

Prolonged survival is associated with absent extraskeletal metastases, which was the case in most patients. Sung et al. reported a median survival after the diagnosis of bone-only metastases of 75 months [95\% confidence interval (CI), 38.6-71.9] with increased survival of de novo bone metastases [13]. The number of patients with de novo and boneonly metastases in our analyses was high at $45 \%$. The comparatively high estimated survival rates emphasize the need for a palliative therapy that is not restricted to pain relief but preserves the patient's physical autonomy.

\section{Conclusion}

The use of a systematic radiological scoring system to classify osteolytic metastases of the vertebral column was shown to be practicable for patients with metastasized breast cancer in the follow-up period after RT, and should be applied in daily routine. The majority of patients showed an improved or unchanged stability of their involved vertebral bodies after 6 months.

\section{Corresponding address}

\section{H. Rief MD, BSc}

Department of Radiation Oncology

University Hospital of Heidelberg

Im Neuenheimer Feld 400

69120 Heidelberg

harald.rief@med.uni-heidelberg.de

\section{Compliance with ethical guidelines}

Conflict of interest. I. Schlampp, S. Rieken D. Habermehl, T. Bruckner, R. Förster, J. Debus, and $H$. Rief state that there are no conflicts of interest.

Open Access. This article is distributed under the terms of the Creative Commons Attribution Noncommercial License which permits any noncommercial use, distribution, and reproduction in any medium, provided the original author(s) and the source are credited.

\section{References}

1. Lutz S, Berk L, Chang E, Chow E et al (2011) Palliative radiotherapy for bone metastases: an ASTRO evidence-based quideline. Int J Radiat Oncol Biol Phys 79(15):965-976

2. Hagberg KW, Taylor A, Hernandez RK et al (2013) Incidence of bone metastases in breast cancer patients in the United Kingdom: results of a multi-database linkage study using the general practice research database. Cancer Epidemiol 37:240-246

3. Berman AT, Thukral AD, Hwang WT et al (2013) Incidence and patterns of distant metastases for patients with early-stage breast cancer after breast conservation treatment. Clin Breast Cancer 13:8894

4. Souchona R, Feyerb P, Thomssenc C et al (2010) Clinical recommendations of DEGRO and AGO on preferred standard palliative radiotherapy of bone and cerebral metastases, metastatic spinal cord compression, and leptomeningeal carcinomatosis in breast cancer. Breast Care 5:401-407

5. Karnofsky DA, Burchenal JH (1949) The clinical evaluation of chemotherapeutic agents in cancer. In: MacLeod CM (Ed) Evaluation of chemotherapeutic agents. Columbia Univ Press, New York, pp 191-205

6. Taneichi H, Kaneda K, Takeda N et al (1997) Risk factors and probability of vertebral body collapse in metastases of the thoracic and lumbar spine. Spine 22:239-245

7. Ebihara H, Ito M, Abumi K et al (2004) A biomechanical analysis of metastatic vertebral collapse of the thoracic spine: a sheep model study. Spine 29:994-999

8. Oda I, Abumi K, Lü D et al (1996) Biomechanical role of the posterior elements, costovertebral joints, and rib cage in the stability of the thoracic spine. Spine 21(15):1423-1429

9. Weber MH, Burch S, Buckley J et al (2011) Instability and impending instability of the thoracolumbar spine in patients with spinal metastases: a systematic review. Int J Oncol 38:5-12
10. Oster G, Lamerato L, Glass AG et al (2013) Natural history of skeletal-related events in patients with breast, lung, or prostate cancer and metastases to bone: a 15-year study in two large US health systems. Support Care Cancer 21:3279-3286

11. Rief H, Bischof $M$, Bruckner T et al (2013) The stability of osseous metastases of the spine in lung cancer-a retrospective analysis of 338 cases. Radiat Oncol 8(1):200

12. Kouloulias VE, Kouvaris JR, Mystakidou K et al (2004) Duration of bisphosphonate treatment: results of a non-randomised study in patients previously treated with local irradiation for bone metastases from breast cancer. Curr Med Res Opin 20:819-826

13. Ahn SG, Lee HM, Cho SH et al (2013) Prognostic factors for patients with bone-only metastasis in breast cancer. Yonsei Med J 54:1168-1177

14. Domchek SM, Younger J, Finkelstein DM et al (2000) Predictors of skeletal complications in patients with metastatic breast carcinoma. Cancer 89:363-368

15. Coleman R, Rubens R (1987) The clinical course of bone metastases in breast cancer. Br J Cancer 77:336-340

16. Rades D, Douglas S, Veninga T et al (2012) Prognostic factors in a series of 504 breast cancer patients with metastatic spinal cord compression. Strahlenther Onkol 188:340-345

17. Rief H, Muley T, Bruckner T et al (2014) Survival and prognostic factors in non-small cell lung cancer patients with spinal bone metastases: A retrospective analysis of 303 patients. Strahlenther Onkol 190:59-63 